International Commission for Alpine Rescue

Commission for Mountain Emergency Medicine
Recommendation REC M 0017 of the Commission for Mountain Emergency Medicine

\author{
of 2004
}

\title{
MEDICAL CONSIDERATIONS IN THE USE OF HELICOPTERS IN MOUNTAIN RESCUE
}

\author{
Iztok Tomazin ${ }^{1^{*}}$ \\ Tim Kovacs ${ }^{2}$
}

Intended for local authorities, rescue organisations and helicopter operators

${ }^{1}$ Mountain Rescue Service of Slovenia, Health Centre Trzic, Potna Mocila 21, SL-4294 Krize,

Slovenia, Phone ++386 45955633 Fax ++386 45955633, E-mail: iztok.tomazin@mf.uni-li.si

${ }^{2}$ Mountain Rescue Association USA, 20726 N. 58 ${ }^{\text {th }}$ Lane, Glendale, AZ 85308-9181, USA,

Phone ++1 602205 4066, E-mail: thovacs@mindspring.com

${ }^{*}$ Corresponding author 
This article reflects the consensus of opinion of the International Commission for Mountain

Emergency Medicine ICAR-MEDCOM which has full responsibility for the content.

Version: 7-21-03

\section{Summary}

The outcome of patient care can be dramatically improved by bringing rapid rescue-medical care to the mountain rescue scene and by rapid transport to a medical facility. The use of helicopter for these purposes is common. It is necessary when it has clear advantages for victims in comparison with ground rescue and transport. Helicopters should work within the existing emergency medical system and must be staffed by appropriate mountain rescue and medically-trained personnel. Activation time should be as short as possible. Activation of a helicopter for a mountain rescue should primarily include indication and assessment of flight and safety conditions. No other mediators or delaying factors should be permitted. The main safety criteria are appropriate mountain rescue and flight training, competence of air and ground crews, radio communication between the air and ground crews, and mission briefing before the rescue. Criteria for a helicopter used for mountain rescue are proper medical and rescue equipment, load capacity, adequate space etc. There are two main groups of indications for use of a helicopter for mountain rescue - the patient's condition and the circumstances at the site of the accident. All persons responsible for the activation of the helicopter rescue operation should be aware of specific problems in the mountains or wilderness.

\section{Keywords}

Wilderness Medicine, Emergency Medicine, Dispatching Centre, Helicopter, Rotary Wing Aircraft, Rescue, Mountain. 


\section{INTRODUCTION}

The Commission recognises that different regions have different rescue systems and that equipment types and availability of helicopters vary widely (Marsden, 1997; Kugler, 1997; Stolpe, 1997; Huguenard, 1997; Hoefliger, 1997; Burillo-Putze et al., 2001). These are suggested minimal requirements for competent and safe response to medical problems in the mountain environment. Unique circumstances may call for unique adaptations to our recommendations, as in developing countries with no formal EMS or rescue system, or in areas with poor resources for formally-trained rescuers, and as in very remote ranges and at very high altitude. For some countries, this may mean using the only resource they have, such as a non-rescue/EMS helicopter with an experienced mountain pilot, plus a crew of a visiting medical provider and a local mountaineer, guide or sherpa. The goal is to provide the "highest level of care available" of capable helicopter, crew, rescuer and medical provider for that response area, and to simultaneously work towards improving that level of care to meet or exceed ICAR recommendations.

The outcome of patient care can be dramatically improved by bringing rapid rescue-medical care to the mountain rescue scene (bringing medical care to the patient rather than the patient to medical care), and by rapid transport to a medical facility. Patients in the mountains and wilderness are commonly subject to extended delays before being able to call for care, receiving care on site and being transported. In many cases of severe injury or illness, delay can compromise recovery or survival (Durrer, 1993; Powell et al., 1997). All persons responsible for the activation of the helicopter rescue operation should be aware of specific problems in the mountains or wilderness.

Medical and rescue personnel should also be aware of all available forms of patient access and transportation so that they may make an informed decision as to the most appropriate methods to employ (Wuerz et al., 1996; Rhodes et al., 1986).

Unnecessary use of helicopters can increase risk to the patient and rescue crew, without improving outcomes.

\section{ACTIVATION AND RATIONAL USE OF HELICOPTERS IN MOUNTAIN RESCUE}

The aim of mountain rescue and emergency medical services is to attend the patient rapidly, provide quality on-scene care, and transport the patient safely to appropriate medical facility (Trunkey, 1995).

The use of a helicopter is necessary when it has clear advantages for victims in comparison with ground rescue and transport (Gabram and Jacobs, 1990; Gearhart et al., 1997). A helicopter which performs mountain rescue should work within the existing emergency medical system. Such a helicopter must be staffed by appropriate mountain rescue and medically-trained personnel (see ICAR recommendation no. 3, Qualifications for Emergency Doctors in Mountain Rescue Operations: "must be comfortable in exposed situations ... conscious of his own safety ... able to work under extreme conditions", Rammlmair et al., 2002) who are part of the official emergency medical system, preferably emergency doctors, with appropriate rescue and medical equipment (Durrer, 1993; Marsigny et al., 1999;

Demartines et al., 1991; Dalton et al., 1992). 


\section{The main goals for using a helicopter are:}

- to provide, as fast as possible, access for a rescue team with appropriately trained medical personnel, according to local systems,

- to provide necessary medical diagnosis and treatment on site,

- $\quad$ to provide fast and gentle transport of victims to the proper medical institution.

\section{Activation of a helicopter for a mountain rescue should include the following criteria:}

- Primary assessment of need by the personnel or bystanders on scene or the dispatch centre. All emergency personnel and dispatch centres should be trained in basic primary assessment of need for specialized wilderness and mountain rescue resources so they can make simple needs decisions (Kovacs, 2002).

- Assessment of flight and safety conditions and availability of the appropriate aircraft.

- No other mediators or delaying factors should be permitted.

The helicopter team which is nearest to the site of accident, with a mountain rescue trained pilot, and with aircraft able to perform the mission in the circumstances in question, and equipped according to regional standards, should be sent out, regardless of service (army, police, private etc), district or state (Tomazin, 2001). The pilot must not only be well trained in the aircraft he or she is operating, but also familiar with the mountain range to which they are responding, and in specific techniques of "rescue flying" (Shimanksi and Kovacs, 2001). Regions with numerous helicopters should position bases to ensure coverage of the widest possible area and optimal response times (maximum 15 minutes). "Activation time" should be as short as possible.

There should be no discrimination between insured and non-insured patients, if they need helicopter rescue. There should be also no discrimination between public/private or paid/unpaid rescue services, but they will be activated based on qualifications and proximity.

\section{Safety criteria:}

- Appropriate mountain rescue flight training / practice and competence of the pilot and aircrew.

- Effective radio communications between the aircrew and ground crew (ICAR Air Rescue Recommendation of $123.1 \mathrm{MHz}$ as standard radio frequency for air to air communication between helicopters of different operators and/or countries. 
- Mission briefing before the rescue is commenced; plan and tasks are made clear to all ground and air personnel.

\section{CRITERIA FOR A HELICOPTER USED FOR MOUNTAIN RESCUE}

- Medical equipment - according to international standards.

- Rescue equipment including a winch and/or 'fixed rope' capability (or 'external load' capability) with releasable double attachment points.

- Load capacity, adequate space and performance for high altitude operations.

- Other HEMS (Helicopter Emergency Medical Services) criteria (according to the ICAR Flight commission's recommendations).

\section{INDICATIONS FOR USE OF A HELICOPTER FOR MOUNTAIN RESCUE}

\section{A) According to the patient's condition (medical indications).}

This type of indication should be determined by the rescue doctor, other medically-trained personnel or dispatch centre, under medical supervision:

- Criteria consistent with NACA (Tryba et al., 1980; Weiss et al., 2001) equal 3 or higher, the need of ALS (Advanced Cardiovascular Life Support, 2000), or ACEP criteria (American College of Emergency Physicians, 1997).

- Injuries, diseases and symptoms which can deteriorate rapidly or during ground transport (head or spine injuries, ischaemic heart disease etc.).

- All other injuries and diseases in which helicopter transport has clear advantages over ground transport, in the opinion of medical personnel at the scene. 


\section{B) According to the circumstances at the site of the accident (rescue/transport indications).}

This type of indication should be determined by the dispatch centre and/or the leader of the rescue intervention, in consultation with the medically-trained personnel:

- Difficult and/or dangerous terrain, when ground rescue would be too dangerous or timeconsuming.

- Time factor, when speed of intervention is very important, for example to finish intervention before darkness or before weather deterioration etc.

- Accidents where there is a high probability that the victim is seriously injured e.g. witnessed fall, crevasse, paragliding crash, avalanche.

- Search missions when it is expected that the victim is ill, injured or exhausted.

- Accidents with many victims, where helicopter(s) can be used as a main or an additional way of transporting victims and/or for rapid transportation of medical personnel and equipment to the site of rescue.

\section{C) Situations where any mechanically capable but not medically equipped helicopter, (qualified for technical rescues but not medically equipped), may be an alternative.}

- Technical rescues (long-line, cable car, etc.).

- Transport of rescue specialists (avalanche, glacier crevasses, canyoning, difficult terrain).

- Transport of rescue equipment.

- Transport of dog-handlers with their dogs.

- Evacuation of non-injured persons.

- Evacuation of ill/injured/exhausted persons meeting IKAR criteria listed above from remote or high altitude locations where more qualified rescue-EMS helicopters or 
personnel are not available but the speed of a helicopter evacuation will likely improve the patient's outcome over a non-helicopter evacuation.

\section{Acknowledgement}

These recommendations have been discussed and officially approved at the annual ICAR MEDCOM meeting in Liechtenstein in 2002 and in Slovenia in 2003 by the following members of the International Commission for Mountain Emergency Medicine: Hermann Brugger (President ICAR MEDCOM, I), Bruno Durrer (President UIAA MEDCOM, CH), Giancelso Agazzi (I), Boris Aleraj (HR), Jan Beaufort (CZ), Roberto Buccelli (I), Joe Dowdall (IRL), John Ellerton (GB), Fidel Elsensohn (A), Gerhard Flora (A), Lapusan Horia (RO), Sylweriusz Kosinski (PL), Tim Kovacs (US), Jan Krzak (PL), Peter Mair (A), Mario Milani (I), Walter Phleps (A), Peter Rheinberger (FL), Marcel Sedlacko (SK), Dario Svajda (HR), Dave Syme (GB), Michael Swangard (CA), Iztok Tomazin (SLO), Xavier Ledoux (F), Igor Zuljan (HR).

\section{Glossary}

ALS: Advanced Life Support. ACEP: American College of Emergency Physicians. HEMS: Helicopter Emergency Medical Service. ICAR: International Commission for Alpine Rescue. NACA: National Advisory Committee on Aeronautics.

\section{References}

Advanced Cardiovascular Life Support (2000). Resuscitation 46: 103-120. American College of Emergency Physicians (1997). Emergency care guidelines. Ann Emerg Med 29: 564-571.

Burillo-Putze G., Duarte I.H., and Alvarez Fernandez J.A. (2001). Helicopter emergency medical service in Spain. Air Med. J. 20: 21-23.

Dalton A.M., Botha A., Coats T., Spalding T., Hodkinson S., Warren C., and Hodgson R. (1992). Helicopter doctors? Injury 23: 249-250.

Demartines N., Meyer C., Scheidegger D., and Harder F. (1991). Helicopter and emergency physician at the accident site. Medicine comparison between altitude and flat land emergency care. Helv. Chir. Acta 58: 223-227.

Durrer B. (1993). Characteristics of emergency therapy in mountain accidents. Ther. Umsch. 50: 228-233.

Gabram S.G., and Jacobs L.M. (1990). The impact of emergency medical helicopters on prehospital care. Emerg. Med. Clin. North Am. 8: 85-102.

Gearhart P.A., Wuerz R., and Localio A.R. (1997). Cost-effectiveness analysis of helicopter EMS for trauma patients. Ann. Emerg. Med. 30: 500-506.

Hoefliger C. (1997). Swiss Air Rescue: REGA. In: Trauma Care. R. Earlam, ed. Saldatore Itd., Hertfordshire; pp. 53-56.

Huguenard P. (1997). Services de l'aide Medicale Urgente en France: SAMU. In: Trauma

Care. R. Earlam, ed. Saldatore Itd., Hertfordshire; pp. 49-52.

Kovacs T. (2002). Model Triage and Dispatch Guidelines for Search and Rescue

Coordinators and Communications Personnel. In: Risks in Mountain Rescue Operations.

Mountain Rescue Association, ed. Poway, California; pp 27-30.

Kugler G. (1997). Concept of the Air Rescue System in Germany (ADAC). In: Trauma Care.

R. Earlam, ed. Saldatore Itd., Hertfordshire; pp. 45-46.

Marsden A. (1997). Patient Air Transport in Scotland: An Integrated Service. In: Trauma Care. R. Earlam, ed. Saldatore Itd., Hertfordshire; pp. 35-36.

Marsigny B., Lecoq-Jammes F., and Cauchy E. (1999). Medical mountain rescue in the Mont Blanc massif. Wilderness Environ. Med. 10: 152-156.

Powell D.G., Hutton K., King J.K., Mark L., McLellan H.M., McNab J., and Mears D. (1997) The impact of a helicopter emergency medical services programs on potential morbidity and mortality. Air Med. J. 16: 48-50.

Rammlmair G., Zafren K., and Elsensohn F. (2002). Qualifications for Emergency Doctors in Mountain Rescue Operations. In: Consensus Guidelines in Mountain Emergency Medicine and Risk Reduction. Elsensohn F., ed. Stefanoni, Lecco; pp. 65-70. 
Rhodes M., Perline R., Aronson J., and Rappe A. (1986). Field triage for on-scene helicopter transport. J. Trauma 26: 963-969.

Shimanski C., and Kovacs T. (2001). Helicopter Operations in Search and Rescue. In: Risks in Mountain Rescue Operations. Mountain Rescue Association, ed. Poway, California; pp. 1518.

Stolpe E. (1997). The First Air Rescue Service in Germany: Christoph 1 Trauma Care. R.

Earlam, ed. Saldatore Itd., Hertfordshire; pp. 46-47.

Tomazin I. (2002). Activation and Rational Use of Rescue Helicopters. In: Consensus

Guidelines in Mountain Emergency Medicine and Risk Reduction. Elsensohn F., ed.

Stefanoni, Lecco; pp. 85.

Trunkey D. (1995). Trauma Systems. A model for Regionalized Care. JAMA 273: 421-422.

Tryba M., Bruggemann H., and Echtermeyer V. (1980). Klassifizierung von Erkrankungen und Verletzungen im Notarztrettungssystem. Notfallmed 8: 725.

Weiss M., Bernoulli L., and Zollinger A. (2001). The NACA scale. Construct and predictive validity of the NACA scale for prehospital severity rating in trauma patients. Anesthesist 50 : 150-154.

Wuerz R., Taylor J., and Smith J.S. (1996). Accuracy of trauma triage in patients transported by helicopter. Air Med. J. 15: 168-170. 